\title{
Nutritional Impacts of Different Whole Grain Milling Techniques: A Review of Milling Practices and Existing Data ${ }^{1}$
}

\author{
Julie Miller Jones, ${ }^{2}$ Judi Adams, ${ }^{3}$ Cynthia Harriman, ${ }^{4}$ Chris Miller, ${ }^{5}$ and Jan Willem Van der Kamp ${ }^{6}$
}

This report was produced with the guidance, advise, and review of the AACCI Whole Grains Working Group: Georgie Aley, Grains \& Legumes Nutrition Council, NSW, Australia; Per Åman, Department of Food Science, BioCenter, Swedish University of Agricultural Sciences, Uppsala, Sweden; Kingsly Ambrose, Department of Grain Science and Industry, Kansas State University, KS, U.S.A.; Alison Baldwin, Campbell Arnott's, North Strathfield, NSW, Australia; Anne Banville, USA Rice Federation (retired), Arlington, VA, U.S.A.; Michelle Bloom, Grains \& Legumes Nutrition Council, NSW, Australia; Richard Braem, TH Foods, Love Park, IL, U.S.A.; Steve Buckholdt, Roman Meal Company, Tacoma, WA, U.S.A.; Jeff Dahlberg, Kearney Agricultural Research \& Extension (KARE), University of California, Parlier, CA, U.S.A.; Brinda Govindarajan, Tesco PLC, U.K.; Joan M. G. Lyon, USDA Center for Nutrition Policy and Promotion (retired), Washington, DC, U.S.A.; Rajen Mehta, Grain Millers, Inc., Eugene, OR, U.S.A.; Mike Orlando, Sunnyland Mills, Cardiff by the Sea, CA, U.S.A.; Kathy Wiemer, General Mills Bell Institute of Health \& Nutrition, Minneapolis, MN, U.S.A.

Although whole grains have long been revered as healthpromoting dietary components, documentation of these health benefits beyond their nutrient contribution is much more recent. In terms of nutrients, whole grains deliver important dietary components such as magnesium and dietary fiber, both of which are often low in Western diets. Beyond nutrient content, the ingestion of whole grains is associated with lower risk of coronary disease, diabetes, hypertension, overweight, and even overall mortality (1). As a result, dietary guidance by a variety of government and health-promoting organizations recommends the inclusion of whole grain foods in the diet. Most guidelines call for an increase in whole grain intake by replacing some refined-grain products $(2,3)$. For example, the U.S. 2005 Dietary Guidelines Advisory Committee (DGAC) recommended that consumers "make at least half their grains whole" (4). The 2010 DGAC continued this recommendation and added that the replacement of refined grains be with at least some high-fiber whole grains (5).

The need to increase consumption of whole grain foods has increased demand for flours and food products that are wholly or partially whole grain. In the United States the quantity of whole wheat flour milled had risen to $5 \%$ of the total flour milled as of June 30, 2011, up from 2\% in 2002 (J. Sosland, Milling and Baking News, personal communication, 2011). According to Mintel, the number of new product launches touting whole grains in their formulations was 20 times greater in 2011 than in 2000 (6). The increase in the number of whole grain products on the market together with the rise in the consumer demand

\footnotetext{
${ }^{1}$ The material in this article is the work of many members of the working group. The views expressed in this article are those of the authors and contributors and do not necessarily reflect the positions or policies of the companies mentioned.

${ }^{2}$ Corresponding author. St. Catherine University emerita, St. Paul, MN, U.S.A. E-mail: jmjones@ stkate.edu; Tel: $+1.651 .690 .6669 ;$ Fax: +1.651 .636 .2394$

${ }^{3}$ Wheat Foods Council, Parker, CO, U.S.A.

${ }^{4}$ Oldways/The Whole Grains Council, Boston, MA, U.S.A.

${ }^{5}$ Engrain, Manhattan, KS, U.S.A.

${ }^{6}$ TNO Food and Nutrition, Zeist, Netherlands.
}

http://dx.doi.org/10.1094/CFW-60-3-0130

○2015 AACC International, Inc. for them (7) has created an opportunity to revisit not only whole grain foods themselves, but also milling processes and their resultant flours and meals.

Consumers expect that whole grain foods and the ingredients used to prepare them will deliver anticipated health benefits. Some sources have voiced concerns that milling processes that separate and combine millstreams may capture fewer whole grain components and their nutrients, fiber, and microconstituents than milling processes that never separate millstreams (8).

Such concerns have been expressed despite the fact that separation and recombination of millstreams have been practiced for much of the history of grain milling. Interestingly, the food intake data linking numerous health benefits and whole grain foods are based on foods using flours produced through the recombination of millstreams. There also are concerns about whole grain foods produced by manufacturers who purchase separate grain components and combine them at the food processing plant (not at the mill). The fear is that they can potentially produce a product that fails to deliver all the whole grain components because manufacturers or millers may not mix the millstreams in the correct proportions, either through error or through an attempt to lessen some of the negative sensory or baking properties imparted by the bran or germ. Thus, the resulting products would contain components that do not comply completely with the definition of a whole grain ingredient.

These concerns were brought to the attention of the AACC International (AACCI) Whole Grains Working Group (WGWG). As a result, the WGWG assessed milling and other practices associated with the production of whole grain flours using publicly available, peer-reviewed scientific evidence. Specifically, the WGWG was interested in the impact of milling practices and methods of whole grain meal or flour preparation on the nutritional quality of flours and foods containing these components as ingredients. In this review, the term "quality" will encompass the impacts of whole grain flour production method on nutrient contribution to the food; bioavailability of macroand micronutrients and phytochemicals; glycemic response; digestibility, bulking ability, and laxative effects; molecular weights and viscosities of fiber components such as $\beta$-glucan; and other relevant components or structures that might affect beneficial health outcomes. 
To that end, in this article we will 1) review the AACCI whole grain definition and various other definitions that have added to or refined this definition; 2) highlight the science that forms the basis of dietary recommendations to increase consumption of whole grain foods; 3) review the history of milling, milling terminology, and current milling practices; and 4) assess whether techniques used to create whole grain foods result in measurable and practical differences in the nutritional quality of whole grain flours and foods. Such an analysis will necessitate a review of stone milling, with and without separation of millstreams by sifting; steel-roller milling, with sifting and recombination of millstreams at the mill; and mixing of mill fractions-bran, germ, and endosperm-in the proportions found in the native kernel in a food processing plant where final products are made. The product of this latter process will be referred to as "reconstituted" whole grain.

\section{Definition of Whole Grains}

Whole grains were formally defined in 1999 by an AACCI ad hoc committee of experts (9). Their goal was to create a definition of whole grains for use by both processors and consumers. It reads:

Whole grains shall consist of the intact, ground, cracked or flaked caryopsis, whose principal anatomical components - the starchy endosperm, germ, and bran-are present in the same relative proportions as they exist in the intact caryopsis.

Other scientific and health-promoting organizations and some regulatory bodies worldwide, including the U.S. FDA and the 2010 Dietary Guidelines for Americans, have adopted the essence of this definition. The AACCI definition has provided the basis for other definitions, which have attempted to make the wording either more consumer-friendly (10) or to reflect the realities of milling practices, as in the refinement of the definition adopted by the European HEALTHGRAIN Consortium in 2009 (11). All whole grain definitions state that they must contain the bran, germ, and endosperm in the same proportions as in the original grain.

\section{Health Benefits of Whole Grains}

Health benefits associated with the consumption of whole grain foods, and the cereal fiber they contain, have been demonstrated in numerous epidemiological studies published over the last 15 years. Cited here are just a few of the many epidemio- logical studies linking whole grain consumption with reduced risk of a number of chronic conditions. Specifically, whole grain consumption has been associated with lower risks of diabetes (12-17), stroke $(18,19)$, overweight and weight gain (20-23), hypertension (24-26), coronary heart disease (27-29), and certain cancers (1,30-32) and with lower mortality for any age $(19,33$, 34). Consistent links with better health outcomes have occurred across widely different population groups, often with culturally very different diet patterns.

Although epidemiological studies show consistent results across studies concerning the health benefits of whole grain consumption, intervention studies have produced mixed results $(35,36)$. Intervention studies often have small numbers of subjects and show the benefits of ingestion of a specific whole grain, such as oats or rye, but not necessarily a mixture of whole grains or brown rice (37-40). Even large randomized intervention trials (41), such as one with healthy overweight subjects in the United Kingdom, have not shown improvements in markers of heart disease with increased intake of whole grain foods compared with usual intake. This study was criticized because the subjects, while overweight, did not carry known markers of coronary disease and might not have been at high risk. Thus, recent reviews have called for more intervention trials. Specifically, Kelly et al. (42) note that "there is a need for well-designed, adequatelypowered, longer term randomized controlled trials (RCTs) in this area." Nonetheless, the positive results of epidemiological studies coupled with the fact that whole grains are a dietary choice with health benefits continue to fuel interest in these foods (31).

\section{Whole Grains and Milling Terminology and Processes}

The majority of epidemiological studies looking at health benefits associated with the intake of whole grain foods have been conducted in Western populations, where breads, cereals, and grain-based foods are primarily wheat based. (Data from the Scandinavian countries would be the exception.) The body of evidence for other population groups also points to health benefits associated with other dietary patterns and whole grain staples (43-45).

In nearly all of these studies, the whole grains consumed would have been kernels processed to remove the husk and outer hull (if a hulled variety). The grains, meals, and flours then would have been treated with one of the following methods prior to consumption. 
1) Whole Grains Minimally Processed or Milled: The grain kernel is left intact or is minimally processed by breaking or flattening the kernel. In some cases, as in ancient times, grain kernels are parched and then boiled. Today, a few whole grain preparations use whole intact kernels. These include foods such as brown rice and soaked wheat kernels or oat groats. Examples of whole grains that have been broken or flattened include cracked wheat or bulgur and steel-cut, pin-milled, or old-fashioned oats.

2) Whole Grain Flours or Meals Produced at the Mill:

a) Single-Stream Milling: The grain is crushed between steel rollers or millstones. All parts of the original kernel stay together from the beginning to the end of the milling process.

b) Multiple-Stream Milling with Recombination: The grain is crushed, and different grain fractions are channeled into separate millstreams. The millstreams may be sifted and separated by particle size. Large particles are often returned to the mill for further grinding to attain flours and meals with desired and uniform particle sizes. The last step in the milling process reunites all the flour streams at the mill so that they have the original proportions of bran, germ, and endosperm in the whole grain flour. This process is called recombination.

3) Whole Grain Flours or Meals Produced Away from the Mill-Reconstitution: When crushed and separated products of milling, specifically the bran, germ, endosperm, and minor milling fractions (from the same grain type), are reunited at the point of use by the food manufacturer, the process is called reconstitution. Manufacturers must exercise diligence to ensure that the proportions of the various components meet the standards set by the AACCI whole grain definition.

Definitions of recombination and reconstitution are provided in the sidebar to clarify why the milling industry refers to these methods in this way.

\section{Reconstituted and Recombined Defined}

Although the definitions of recombination and reconstitution provided in the Merriam-Webster Dictionary do not refer to milling directly, they are included here because they shed light on the common understanding of these words.

Recombine (transitive verb)

1: to combine again or anew

2: to cause to undergo recombination

Recombine (intransitive verb)

1: to undergo recombination

\section{Reconstitute (verb)}

1: to restore (food, etc.) to its former or natural state or a semblance of it, as by the addition of water to a concentrate: e.g., reconstituted lemon juice

2: to reconstruct; form again
An In-depth Look at Types of Whole Grain Flour Products

In this section, whole grain meal and flour products obtained through reconstitution and recombination of multiple millstreams are compared in greater detail with those obtained from single-stream milling, and the contribution they make to whole grain intake in the United States and other countries with similar practices is discussed. (Note, in this section the term "flour" is used to refer to all granulations, including various meals.)

Intact and Minimally Processed Grains. Preparation of grains for eating may be as simple as removal of the inedible husk, leaving the kernel with its bran, germ, and endosperm virtually unchanged. In some grains, such as bulgur (wheat) or oats, heating or kilning is used to prevent rancidity and maintain nutrient quality. Other grains, such as dark varieties of millet and sorghum, are soaked prior to grinding to lower tannin content and improve digestibility and nutrient availability. Soaking of corn in water with lime (calcium oxide), called nixtimalization, improves the availability of certain essential amino acids and releases the niacin from niacytin, which are both important for the prevention of niacin deficiency (pellagra). Soaking the intact grain also may help to hydrate and soften the grain, shorten the cooking time, facilitate starch gelatinization, and increase the availability of nutrients. Such factors increase the use and nutritive contribution of certain grains.

Brown and wild rices, cooked whole oat groats, and wheat and rye berries (kernels) are examples of traditional cereals that are eaten as entire kernels. Other techniques may also be applied to intact grains so they can be utilized for human food. These include toasting, parching, popping, scoring, or minimal abrasion (polishing or pearling). Such minimal processing is necessary to allow grains to absorb water, gelatinize the starch, shorten the cooking time, release some tightly bound vitamins and minerals, and increase amino acid availability. This processing also facilitates chewing and digestion and ultimately helps provide needed nutrients. Examples of minimal processing include rolling (pressing the grain between heated rollers) of oat groats or rye berries to make oatmeal or rye porridge, cracking the grain to make steel-cut (also called pin-milled or Irish) oats, slight toasting of the cracked kernel to make bulgur (wheat), parching corn, or popping kernels (as with popcorn). These procedures may involve heat and pressure.

Although such processes have the capacity to decrease the concentration of one or more nutrients or phytonutrients, they also can increase the bioavailability of some nutrients and stabilize nutrients, especially fat-soluble ones, in the bran and germ, making them less susceptible to oxidative rancidity. Thus, such treatments can prevent the loss of important vitamins such as vitamin $\mathrm{E}$ and essential fatty acids. Although more whole grains are eaten after some form of minimal processing than in their intact whole form, minimally processed forms of whole grains are still minor contributors to overall whole grain intake $(13,14$, 27,46,47).

Single-Stream Milled Grains. In single-stream milling, all the grain placed in the hopper and constituting a single batch is kept together during the entire crushing process. Grains may be crushed between millstones or steel rollers. Although some believe that both the input and output of the mill are from a single grain variety, this is rarely the case. Usually, a blend of grain varieties is placed in the hopper prior to crushing to minimize variations in protein or other quality aspects of the end products caused by innate differences in varietals or growing conditions. 
The contribution of single-stream milling to whole grain foods in Western diets is minimal, and an even tinier fraction comes from stone mills. This is due, in part, to differences in the efficiency of stone milling versus roller milling. An average stone mill grinds $\approx 2,000 \mathrm{lb}$ of flour/hr, while a steel-roller mill has an output of $\approx 3$ million pounds of flour/day. Stone milling requires an experienced operator whose direct monitoring of the mill ensures that the flour is always between the stones, the flour is not too coarse or too fine, and the stones are not generating too much friction and heat (48). Too much friction can not only burn the flour, the sparks can ignite the flour dust, so the miller must be present to smell the air and taste the flour to make sure that the flour is not burnt or causes a fire. In contrast, modern steelroller mills are computer controlled.

Whole Grain Flour-Recombined. The majority of whole grain flours are made by recombining millstreams at the mill. Although the starting material can be a single variety of grain raised in a single location, this is rare. Most mills combine a mix of grains from different locations. This helps mills produce flours that are consistent in terms of water absorption and other characteristics desired by end users.

In the multiple-stream process, different millstreams are separated by particle size and other characteristics. Particles that are too large may be returned to be reground until they reach the correct size. Before leaving the mill, all the various millstreams are recombined to become whole grain flour that will have the proportions of bran, germ, and endosperm that are characteristic of the grains in the original batch.

To ensure that nothing is lost during the milling process, grain millers employ the concept of "mass balance," i.e., the mass of grain at the start and end of the milling process is the same (minus a minor correction for moisture loss that occurs during processing). In Europe flour may be recombined according to an established percentage rather than using mass balance. Thus, whether from single- or multiple-stream processes, the resulting whole grain flour directly reflects the composite of grains used at the start of the milling operation. The practice of recombination was formally recognized by the U.S. Food and Drug Administration (FDA) in the U.S. Code of Federal Regulations as early as 1941 (49).

Whole Grain Flour-Reconstituted. Reconstituted whole grain flours are those made by blending the bran, germ, and endosperm of a single grain type (e.g., wheat) in the proportions that exist in an intact kernel. Various separated streams from different process lots, vendors, or batches, which may have been purchased separately, are joined with their counterparts away from the mill. Thus, other divisions of a company or other companies may purchase bran, germ, and endosperm of the same grain type and reconstitute them into a whole grain flour to sell or integrate them "at the mixing bowl" to arrive at the same original proportions of bran, germ, and endosperm characteristic of the grain type (50).

The blending is usually done by end users of the grain, usually makers of specialty flours or manufacturers of whole grain foods. The meals, flours, and food products produced in this way are referred to as reconstituted. To ensure that the proportions of bran, germ, and endosperm are representative of the intact seed or kernel, reconstituted whole grain flours and meals must be blended with precision. Some have suggested that safeguards are needed to ensure that all the fractions are present and that the ratios are not "tweaked" to improve bread quality or other sensory or functional characteristics.
Some countries, such as the Netherlands, have certification programs for whole grain flours delivered to bakers. In this example the Netherlands Bakery Center certification program includes criteria for flour composition and protocols for announced and unannounced inspections. The latter is one strategy to verify that whole grains produced by any method of milling meet the established criteria.

Whole Grains in the Food Supply. Whole grain intake, as measured in epidemiological studies for determining baseline consumption or intake during the study, is typically measured using food frequencies or analogous instruments. As a result, any nutritional analysis or associations with health outcomes would reflect the whole grain foods in the marketplace. Thus, most of the associations linking reduced disease risk and whole grain consumption are derived from grains processed into flours produced either by recombination or reconstitution.

\section{History of Milling}

Archeological digs have unearthed querns and other milling devices from ancient civilizations all over the world. Critics of food processing and modern milling often suggest that separate millstreams and sifting are modern phenomena. Thus, a brief review of milling's long history is important.

In stone milling, grain kernels are often crushed between two stones-a stationary stone and a stone that rolls or presses on the grain. Methods for turning the stone have changed over time, but the net result is a single-stream milling process.

The practice of blending grain varieties and employing sifting and recombining also has a long history. The Greeks and Romans preferred white bread. The Romans sifted wheat into seven grades of flour, often using woven horsehair or papyrus in baskets as sifters. Sifting enabled cleaning of foreign materials from the wheat and separation of various grain particles.

According to Pliny (A.D. 70), Roman millers and bakers mixed varieties to achieve a desired end product. He wrote about combining varietals as follows, "The wheat of Cyprus is swarthy and produces a dark bread, for which reason it is generally mixed with the white wheat of Alexandria." Lighter colored breads were considered a status symbol in Roman culture. Bread made from unrefined, unsifted flour was thought to be suitable only for the lower classes, slaves, and gladiators. During the 1st century A.D., bread made from sifted flour was produced on a large commercial scale throughout much of the Roman world.

As early as the 15 th century, mills were documented as using bolting cloths of linen and other woven materials to separate the white flour from the bran. Old mills had decorated wooden bran pukers (Kleiekotzer in German), which "puked" bran. This bran was very rarely added back into the flour (recombined) because it contained stones and dirt. Instead, it was usually used as feed.

In colonial New England wheat was milled and sifted into white flour by removing the bran and middlings. The middlings, also called "ships stuff" or "red dog," was used for "ships biscuits." Red dog was named after a Native American who traded for all of the middlings the miller could supply his tribe. Bran was considered worthless and tossed into streams.

The Industrial Revolution brought many changes, including multistory water-powered millhouses, rotating sifting reels and shakers, and woven wire-mesh sifters or silk bolting cloths that were used to sift refined flour to an even finer particle size. The process of separating millstreams continued to reflect the desir- 
ability of white flours, while bran, red dog, and other streams were not highly prized.

Whole grains remained the mainstay of peasant breads. In most early mills, when the bran and germ fractions were added back into the refined flour to make whole grain flour, the process would have met the definition of recombination rather than single-stream milling. Thus, recombination is not a new process and is not associated only with modern steel-roller milling.

Water-driven stone mills built by colonists and pioneers used sifting techniques (often involving hand sifting, calling sanitation into question) to separate crushed particles by size. Large particles were reground and recombined after they attained the desired size. By the beginning of the 19th century, before the advent of roller mills, complex mills with multiple millstones and separated millstreams were commonplace.

Few mills today crush grain without separating millstreams, and even fewer mills use stones.

\section{Impact of Different Milling Processes on Nutrients}

Some claim that only whole, intact, or unprocessed grains can deliver health and nutritional benefits. However, this is not borne out by scientific data. Studies show that the nutritional value of whole grains may actually be improved by milling and processing, which increase digestibility and the availability of amino acids (1), minerals (51), and vitamins (52). Such studies also suggest that moderate heat and humidity encountered during milling inactivates enzymes in the flour, which is beneficial because it inhibits the enzymatic promotion of the breakdown of lipid components and antioxidant vitamins. Enzyme inactivation means that flours could potentially have greater vitamin retention and decreased activity of heat-sensitive antinutritional factors (53).

Whole grain flours are inherently less stable than refined flours. One website (54) suggests that whole grain flour produced by grinding between two stones may require refrigeration because some of the oil pressed out of the germ can be heated to $60^{\circ} \mathrm{C}$ or higher, temperatures which can trigger rancidity. In addition, oil from the germ can gum up the milling equipment, causing a problem known as "loading." Nutritionally, the oil on the stone can result in both the loss and oxidation of fat-soluble components such as tocopherol and polyunsaturated fatty acids. Further, the oil can trap some of the flour components.

A study conducted at the French Institut National de la Recherche Agronomique (INRA) showed that stone-ground flours have higher levels of damaged starch than those produced by other milling methods (55). Although some damaged starch is necessary for bread production, high levels not only impair baking but also change the glycemic response of foods made from such grains.

Some websites and authors suggest that flour milled between stones (which has neither been separated nor recombined) delivers more nutrients than grains crushed between metal rollers. This theory is based on the supposition that grains crushed by stones would not reach a temperature as high as grains crushed by steel rollers. However, this is only true if the grinding is very slow and labile components are not exposed to temperatures that enhance vitamin loss (56).

A study comparing roller, plate, hammer, and stone mills showed that the highest temperatures were generated when grinding wheat between stones, with temperatures reaching as high as $90^{\circ} \mathrm{C}$. In contrast, roller mills reached temperatures of $35^{\circ} \mathrm{C}$, and plate and hammer mills reached intermediate tem- peratures within this range. In a study by Prabhasankar and Rao (57), whole wheat flour obtained from stone- or plateground wheat showed greater loss of total amino acids than hammer- and roller-milled samples. Unsaturated fatty acid content, particularly linolenic acid, was lower in stone-milled flour compared with roller-milled flour. This same pattern of greater losses in stone-milled flours was seen with both hard and soft wheats and flours with both weak and strong (high) gluten (57). These data suggest that roller-milled whole grain flours deliver a higher level of unsaturated fatty acids than stonemilled flours.

Studies of milled barley further substantiate findings that roller milling results in lower temperatures than stone milling. Complete retention of amylase activity in barley flour after steel-roller milling indicates there is minimal heat impact from steel-roller milling. This may be due in part to the high efficiency of roller mills, which minimize the length of time flour particles touch the steel rollers (C. Miller, Engrain [formerly Buhler Instructor of Milling, Kansas State University], personal communication, 2011). Bakers are very interested in the retention of amylase activity because this activity is critical in baking. Excess heat denatures some proteins and alters other functional flour components, thus amylase activity may serve as the "canary in the coal mine," because too much heat could signal the potential for problems in baking properties and nutrient loss.

Large particle size and high extraction resulting from milling, especially milling that involves a single pass through a stone mill, also can affect the bioavailability of iron, zinc, and calcium (58-61). (This may be especially true for hard wheats, which are less well crushed using stone milling techniques.) Despite the presence of many minerals in whole grain foods, their availability for absorption in the body may be impaired (62). This can be a particular problem if grains contain high levels of the potent metal chelator phytate, which impairs mineral bioavailability (63). Whole grain cereals and legumes contain $\approx 600 \mathrm{mg}$ of phytate/100 g, dry weight.

Impairment of bioavailability is intensified if the minerals are trapped in the grain matrix, as occurs with large particles. The effect of particle size has been demonstrated in studies with corn kernels ground to various particle sizes. Results showed that large particles were less likely to be acted upon during fermentation by phytase enzymes; as a result, the final product showed lower bioavailability of many minerals (61). Thus, higher phytate levels and larger particles can translate into lower mineral absorption. A recent study showed that the nutrient bioavailability of whole grain wheat increased after micromilling (64). Smaller particle size also may impact vitamin availability. In a study by Yu and Kies (65), B vitamins were found to be more available from maize bran products when the particle size was small.

Roller milling may be beneficial compared with stone milling in terms of dietary fiber. Studies conducted at the Canadian Grain Commission found higher amounts of total fiber and cholesterol-lowering $\beta$-glucan in barley that was roller milled than in barley that was stone milled (66-69). This was true for every barley variety tested. The data also showed that $\beta$-glucan content decreased when the grain was germinated or glucanases were not controlled. Both of these findings provide another argument for improved nutritional function through mild heat stabilization of millstreams for grains with high enzymatic activity. Unlike the positive effect of small particle size on vita- 
min and mineral availability, larger particles of barley had higher levels of certain fibers such as $\beta$-glucan (70). However, dry milling of oats did not affect the molecular weight of the $\beta$-glucan (71).

When comparing nutrients affected by different milling techniques, it is important to ascertain that differences are ascribable to the milling process and not to different extraction rates or other aspects of the grain, such as varietal differences. Some studies showing advantages of stone milling over roller, plate, or hammer milling do not compare the same extraction rates. In addition, a comparison of methods must not only look at nutrient content, but also at bioavailability to determine the actual amount of nutrient absorbed.

\section{Nutritional Advantages of Separated-Stream Milling: Stabilization and Consistency}

Historically, white flour has been favored over whole grain flour for several reasons. One reason is its ability to create a fine cell structure and more products; other reasons include its cleanliness (e.g., no stones, etc.) and stability. In addition, the unsaturated lipids in the bran and germ portion of whole grain flour can quickly go rancid.

Modern milling technology enables grain components to be separated and stabilized. After stabilization they are recombined with the other components from the original kernel. For example, heat treatment can reduce the activity of a large number of the lipases in the bran. This is extremely important for some flours, such as brown rice flour (72). Without stabilization the availability of brown rice flour would decrease dramatically, and the cost of all products made from it would increase because of its short shelf life. Further, the possibility of ingesting oxidized fats and their free radicals would increase. This would have negative health consequences, including increased inflammation and risk of various chronic diseases (73). Thus, for whole brown rice flour, as well as other flours, the ability to separate the bran and germ fractions and to stabilize components prior to adding them back to make whole grain flours is critical for both product quality and human health.

Consistency is another advantage of recombination of multiple streams at the mill. Grains, like all foods, vary widely in their nutritional and water contents depending on the variety and growing conditions from place to place and year to year (discussed below). Selection of an optimal mix of varieties allows mills to produce flours and meals that not only have consistent baking qualities from batch to batch, but that also deliver consistent levels of macro- and micronutrients. This consistency enables bakers and other end users of all flours to produce successful products from standardized formulations and helps assure consumers a product is safe and nutritious.

\section{Other Key Factors Affecting Nutrients in Whole Grains}

Milling method is only one of the potential factors affecting nutrients in whole grains. In fact, three other factors have a much more powerful impact on the macro- and micronutrients in whole grains:

- Differences in grain varietals and cultivars

- Growing conditions (soil, climate, weather, etc.)

- Subsequent processing (baking, extruding, etc.)

Variability in the proximate composition of whole grain wheat in Germany over a 10 year period (2000-2010) is shown in
Table I (M. G. Lindhauer, personal communication, 2011). The percentages in Table I are indicative of variation in macroconstituents, revealing a nearly twofold variation in protein, dietary fiber, and minerals. Similar data for Denmark is provided in Table II (J. W. van der Kamp, personal communication, 2011). These data show slightly lower variability in whole wheat flours in Denmark than was observed in Germany. (The somewhat lower degree of variability would be expected because the land and climatic conditions vary less in the smaller country, which has fairly homogeneous topography and weather.) Similar variations were observed within species across varieties and growing regions in an extensive study undertaken as part of the European HEALTHGRAIN Project $(74,75)$.

The vitamin content of whole grains, similar to their proximate composition, varies by cultivar and growing conditions (76). The data in Table III show that B vitamins vary two- to threefold, and loss varies among the vitamins. One study showed $95 \%$ of the pyridoxine in the original wheat kernel was retained in milled whole wheat flour, and $80-100 \%$ of the thiamin was retained.

Any decreases in B vitamin content caused by milling are then carried through into the bread and other end products (63). Losses due to milling pale in comparison to vitamin losses in products made with alkaline leavenings such as baking soda, those cooked with a lot of water, or those held for long periods at high temperature, such as occurs on steam tables. For yeast breads, thiamin losses have been shown to vary from 31 to $56 \%$ (77). However, the type and length of fermentation also impact nutrient content, availability, and digestibility in whole grain products (78). Long fermentations increase riboflavin by $30 \%$ and nearly double the thiamin content but reduce the pyridoxine content by half. Further, long fermentations and sourdough may increase mineral bioavailability and improve protein digestibility. Thus, the milling method used may have much less impact on the final nutrient content than other factors.

Table I. Variation in proximate composition of whole wheat flours in Germany (2000-2010) ${ }^{\mathrm{a}}$

\begin{tabular}{lc}
\hline Constituent & Range (\% dry matter) \\
\hline Protein & $8-18$ \\
Carbohydrates & $78-88$ \\
Dietary fiber & $9-15$ \\
Crude fat & $1.5-2.2$ \\
Minerals & $1.4-2.8$ \\
\hline
\end{tabular}

${ }^{a}$ M. G. Lindhauer, personal communication, 2011.

Table II. Variation in proximate composition of whole wheat flours in Denmark ${ }^{\mathrm{a}}$

\begin{tabular}{lccc}
\hline Constituent & Average & Range & $N$ \\
\hline Dietary fiber & 11.6 & $9.9-13.8$ & 14 \\
Total fat & 2.4 & $2.0-2.7$ & 13 \\
Ash & 1.5 & $1.2-1.8$ & 14 \\
\hline
\end{tabular}

${ }^{a}$ J. W. van der Kamp, personal communication, 2011.

Table III. Variability in B vitamin contents in whole grain wheat ${ }^{\mathrm{a}}$

\begin{tabular}{lc}
\hline Vitamin & Range $(\boldsymbol{\mu g} / \mathbf{1 0 0} \mathbf{g}$, dry matter $)$ \\
\hline Thiamin & $260-613$ \\
Riboflavin & $48-106$ \\
Pyridoxine & $145-316$ \\
\hline
\end{tabular}

${ }^{a}$ Batifoulier et al. (76). 


\section{Best Practices in Milling and Manufacturing Support Increased Whole Grain Consumption}

Support for milling and manufacturing processes that maintain the integrity and nutritional benefits of whole grain constituents, while enabling increased availability of whole grain products, facilitates the important goal of increasing whole grain consumption. Thus, definitions such as the 2009 European HEALTHGRAIN definition that recognize and enfranchise current milling practices are important. Specifically, the HEALTHGRAIN definition states that recombination is acceptable. It further notes that a whole grain with the loss of a small amount of the bran carrying undesirable components (e.g., heavy metals or mycotoxins) may be an important practical modification that will result in the objective of improved health better than rigid adherence to a definition that allows no leeway for improvements in milled grain safety. The HEALTHGRAIN definition of whole grains states (79):

Whole grains consist of intact, ground, cracked or flaked kernel after the removal of inedible parts such as the hull and husk. The principal anatomical components-the starchy endosperm, germ and bran-are present in the same relative proportions as they exist in the intact kernel.

- Temporary separation of whole grain constituents during processing for later recombination is acceptable.

- Small losses of components-i.e. less than $2 \%$ of the grain $/ 10 \%$ of the bran-that occur through processing methods consistent with safety and quality are allowed.

- Removal of the very outer bran layer-up to $10 \%$ of the bran or $2 \%$ of the grain-is acceptable for minimising levels of undesirable substances such as bacteria, molds, agrochemicals and heavy metals.

-Milling and processing

- Whole grain foods are almost universally processed to make them edible and safe for human consumption.

- Whole grain includes grains that have been subjected to processing but only if, after processing, the germ, endosperm and bran are present in the same, or virtually the same, proportions as in the original grain.

- Temporary separation of whole grain constituents during processing for later recombination is acceptable, provided the proportions of the germ, endosperm and bran are the same or virtually the same as in the original grain.

- Recombination of bran, germ and endosperm from the same type and variant of grain in which a component (bran, germ or endosperm) has been stabilised is allowed provided that the three components are in the correct proportions.

- Recombination of the endosperm, bran and germ takes into account that there are variations in the ratio of endosperm, bran and germ between kernels in one ear and between varieties of one type of grain. Recombination per grain and per variety will result in some fluctuations in the ratios of endosperm, bran and germ between batches of flour and products. There should, however, be no significant nutritional losses, and differences should be no greater than normally found from season to season or between varieties.

The various bullet points attached to the HEALTHGRAIN definition of whole grains recognize current industry practices, noting that temporary separation, stabilization, and recombination of millstreams as practiced in modern milling and cereal manufacture are acceptable. The definition also highlights the variability that exists in grain, so the ratio of bran, germ, and endosperm is not a fixed standard. The definition allows for removal of small amounts of the outer layers through techniques such as peeling of very thin outer layers of a grain kernel to reduce unwanted components and their potential toxicity. Investigators at VTT in Finland have shown that minimal peeling increases bran utilizability, improves safety (through removal of surface mycotoxins, pesticides, and herbicides) and does not impact nutrient bioavailability (80).

Research is needed to improve the nutritive quality of grain and ensure that milling procedures maximize the quality and nutritive value of milled whole grains. Nevertheless, innovations to improve both breadmaking potential and availability of nutrients from whole grains mandate ongoing vigilance in practices and refinement of definitions and their application. Such an effort will encourage change and make certain that rigid application of definitions does not prevent adoption of practices that might improve nutrient bioavailability, product safety, or product affordability and consumer acceptance. It will also mean that new techniques and processes that might cause a decrease in whole grain nutritional value or safety will be scrutinized.

\section{Conclusions}

Whole grain flours are produced using different milling techniques. The majority of whole grain flour is produced using modern milling techniques, usually with steel rollers, through processes in which a batch of grain is separated into multiple millstreams, sifted, and then recombined. In other cases constituent millstreams are purchased and combined by a supplier or end user to achieve a reconstituted whole grain flour or meal that has the desired functional, food safety, and nutritional properties. In a very small number of cases whole grain flours are stone-ground, with the grain kernels crushed between rotating stones. The techniques of separating, sifting, and recombining millstreams have been practiced for centuries.

A significant proportion of whole grain flour or meal consumed in Western countries is produced in mills where the millstreams are separated and either reconstituted or recombined. The positive health benefits associated with whole grain consumption are derived from and have been documented in epidemiological studies on whole grain foods from grains produced through modern milling techniques (generally with steel rollers), in which the millstreams either were recombined at the mill or grain components were reconstituted to the correct proportions at the plant. If recommendations for increased consumption of whole grains are to be met, consumers need to be encouraged to consume whole grain foods produced by all milling methods.

Existing data comparing single-stream milling and multiplestream milling with recombination do not show any strong advantage for either milling method. Little, if any, publicly available data exist that show there is a decrease in nutritional value with multiple-stream milling using either recombination or reconstitution "at the mixing bowl." In fact, the separation of millstreams, as in the milling of brown rice, allows for highly labile brans and germs to undergo a stabilization treatment to make them less susceptible to rancidity. The net result is greater safety, increased stability, and higher nutrient retention.

Data comparing use of stones and steel rollers in milling, in most cases, show there is improved nutrient retention, improved 
protein availability, and higher dietary fiber retention for grains such as barley when steel-roller mills are used. The alleged hightemperature destruction of nutrients with steel rollers has not been documented, and the high throughput rate means the shorter contact time between the grain and the rollers results in less loss of unsaturated lipids and greater enzyme activity and nutrient retention.

Small differences in nutrient amount or availability caused by differences in whole grain milling practices must also be viewed in the context of the wider variations caused by differences in variety, agronomic conditions, and region of cultivation. Such variability must be considered when comparing batches of flour prepared by many different methods. Further processing into breakfast cereals, breads, crackers, and other products can enhance or diminish the nutrient quality of the resulting foods. Research to improve the acceptability and variety of whole grain products derived from any milling method would be an effective use of resources. Such efforts could improve whole grain consumption and, with that, produce an increase in the consumption of the important nutrients and phytochemicals that whole grains provide.

In summary, the AACCI Whole Grains Working Group supports increasing whole grain intake through the use of intact whole grains and grains milled with the use of stones and steel rollers in single-stream milling, multiple-stream milling where streams are recombined at the mill, and multiple-stream milling in which whole grains are responsibly reconstituted "at the mixing bowl."

\section{References}

1. Jonnalagadda, S. S., Harnack, L., Liu, R. H., McKeown, N., Seal, C., Liu, S., and Fahey, G. C. Putting the whole grain puzzle together: Health benefits associated with whole grains-Summary of American Society for Nutrition 2010 Satellite Symposium. J. Nutr. 141: 1011S, 2011.

2. Singapore Health Promotion Board. Whole-grains: The wise choice! Published online at www.hpb.gov.sg/HOPPortal/health-article/6360. The Board, Singapore, 2012.

3. Folloni, S., and Ranieri, R. Whole grain products in (Southern) Europe: Consumer trends and technological implications. In: Proceedings Whole Grains Summit 2012. CFW Plexus DOI: http://dx. doi.org/10.1094/CPLEX-2013-1001-22B. 2013.

4. U.S. Department of Agriculture and U.S. Department of Health and Human Services. Dietary Guidelines for Americans, 2005, 6th ed. Published online at www.health.gov/dietaryguidelines/dga2005/ document. U.S. Government Printing Office, Washington, DC, 2005.

5. U.S. Department of Agriculture and U.S. Department of Health and Human Services. Dietary Guidelines for Americans, 2010, 7th ed. Published online at www.cnpp.usda.gov/DietaryGuidelines. U.S. Government Printing Office, Washington, DC, 2010.

6. Whole Grains Council. Whole grain statistics. Published online at www.wholegrainscouncil.org/newsroom/whole-grain-statistics. The Council, Boston, 2011.

7. International Food Information Council Foundation. 2013 Food and Health Survey: Consumer attitudes toward food safety, nutrition and health. Published online at http://old.foodinsight.org/ LinkClick.aspx?fileticket $=$ spavtJtVkzM\%3d\&tabid=1482. IFIC Foundation, Washington, DC, 2013.

8. Ortiz, J. Local grain, whole grain milling. Bread Lines 19(March), 2011.

9. AACC International. Whole grains definition. Published online at www.aaccnet.org/initiatives/definitions/Pages/WholeGrain.aspx. The Association, St. Paul, MN, 1999.

10. Whole Grains Council. Definition of whole grains. Published on- line at www.wholegrainscouncil.org/whole-grains-101/definitionof-whole-grains. The Council, Boston, 2004.

11. van der Kamp, J. W., Poutanen, K., Seal, C. J., and Richardson, D. P. The HEALTHGRAIN definition of 'whole grain.' Food Nutr. Res. 58:22100, 2014.

12. Fung, T. T., Hu, F. B., Pereira, M. A., Liu, S., Stampfer, M. J., Colditz, G. A., and Willett, W. C. Whole-grain intake and the risk of type 2 diabetes: A prospective study in men. Am. J. Clin. Nutr. 76:535, 2002.

13. Liu, S., Manson, J. E., Stampfer, M. J., Hu, F. B., Giovannucci, E., Colditz, G. A., Hennekens, C. H., and Willett, W. C. A prospective study of whole-grain intake and risk of type 2 diabetes mellitus in US women. Am. J. Public Health 90:1409, 2000.

14. Murtaugh, M. A., Jacobs, D. R., Jr., Jacob, B., Steffen, L. M., and Marquart, L. Epidemiological support for the protection of whole grains against diabetes. Proc. Nutr. Soc. 62:143, 2003.

15. Lutsey, P. L., Jacobs, D. R., Jr., Kori, S., Mayer-Davis, E., Shea, S., Steffen, L. M., Szklo, M., and Tracy, R. Whole grain intake and its cross-sectional association with obesity, insulin resistance, inflammation, diabetes and subclinical CVD: The MESA Study. Br. J. Nutr. 98:397, 2007.

16. de Munter, J. S., Hu, F. B., Spiegelman, D., Franz, M., and van Dam, R. M. Whole grain, bran, and germ intake and risk of type 2 diabetes: A prospective cohort study and systematic review. PLoS Med. 4:e261, 2007.

17. Parker, E. D., Liu, S., Van Horn, L., Tinker, L. F., Shikany, J. M., Eaton, C. B., and Margolis, K. L. The association of whole grain consumption with incident type 2 diabetes: The Women's Health Initiative Observational Study. Ann. Epidemiol. 23:321, 2013.

18. Liu, S., Manson, J. E., Stampfer, M. J., Rexrode, K. M., Hu, F. B., Rimm, E. B., and Willett, W. C. Whole grain consumption and risk of ischemic stroke in women: A prospective study. J. Am. Med. Assoc. 284:1534, 2000.

19. Fung, T. T., Stampfer, M. J., Manson, J. E., Rexrode, K. M., Willett, W. C., and $\mathrm{Hu}$, F. B. Prospective study of major dietary patterns and stroke risk in women. Stroke 35:2014, 2004.

20. Liu, S., Willett, W. C., Manson, J. E., Hu, F. B., Rosner, B., and Colditz, G. Relation between changes in intakes of dietary fiber and grain products and changes in weight and development of obesity among middle-aged women. Am. J. Clin. Nutr. 78:920, 2003.

21. Bazzano, L. A., Song, Y., Bubes, V., Good, C. K., Manson, J. E., and Liu, S. Dietary intake of whole and refined grain breakfast cereals and weight gain in men. Obes. Res. 13:1952, 2005.

22. O’Neil, C. E., Zanovec, M., Cho, S. S., and Nicklas, T. A. Whole grain and fiber consumption are associated with lower body weight measures in US adults: National Health and Nutrition Examination Survey 1999-2004. Nutr. Res. 30:815, 2010.

23. McKeown, N. M., Troy, L. M., Jacques, P. F., Hoffmann, U., O’Donnell, C. J., and Fox, C. S. Whole- and refined-grain intakes are differentially associated with abdominal visceral and subcutaneous adiposity in healthy adults: The Framingham Heart Study. Am. J. Clin. Nutr. 92:1165, 2010.

24. Flint, A. J., Hu, F. B., Glynn, R. J., Jensen. M. K., Franz, M., Sampson, L., and Rimm, E. B. Whole grains and incident hypertension in men. Am. J. Clin. Nutr. 90:493, 2009.

25. Wang, L., Gaziano, J. M., Liu, S., Manson, J. E., Buring, J. E., and Sesso, H. D. Whole- and refined-grain intakes and the risk of hypertension in women. Am. J. Clin. Nutr. 86:472, 2007.

26. Kochar, J., Gaziano, J. M., and Djoussé, L. Breakfast cereals and risk of hypertension in the Physicians' Health Study I. Clin. Nutr. 31:89, 2012.

27. Jacobs, D. R., Jr., Meyer, K. A., Kushi, L. H., and Folsom, A. R. Wholegrain intake may reduce the risk of ischemic heart disease death in postmenopausal women: The Iowa Women's Health Study. Am. J. Clin. Nutr. 68:248, 1998.

28. Liu, S., Stampfer, M. J., Hu, F. B., Giovannucci, E., Rimm, E., Manson, J. E., Hennekens, C. H., and Willett, W. C. Whole-grain consumption and risk of coronary heart disease: Results from the 
Nurses' Health Study. Am. J. Clin. Nutr. 70:412, 1999.

29. Steffen, L. M., Jacobs, D. R., Jr., Stevens, J., Shahar, E., Carithers, T., and Folsom, A. R. Associations of whole-grain, refined-grain, and fruit and vegetable consumption with risks of all-cause mortality and incident coronary artery disease and ischemic stroke: The Atherosclerosis Risk in Communities (ARIC) Study. Am. J. Clin. Nutr. 78:383, 2003.

30. Schatzkin, A., Park, Y., Leitzmann, M. F., Hollenbeck, A. R., and Cross, A. J. Prospective study of dietary fiber, whole grain foods, and small intestinal cancer. Gastroenterology 135:1163, 2008.

31. Jones, J. M., and Anderson, J. W. Grain foods and health: A primer for clinicians. Physician Sportsmed. 36:18, 2008.

32. Aune, D., Chan, D. S., Lau, R., Vieira, R., Greenwood, D. C., Kampman, E., and Norat, T. Dietary fibre, whole grains, and risk of colorectal cancer: Systematic review and dose-response metaanalysis of prospective studies. Br. Med. J. 343:d6617, 2011.

33. Jacobs, D. R., Jr., Andersen, L. F., and Blomhoff, R. Whole-grain consumption is associated with a reduced risk of noncardiovascular, noncancer death attributed to inflammatory diseases in the Iowa Women's Health Study. Am. J. Clin. Nutr. 85:1606, 2007.

34. Wu, H., Flint, A. J., Qi, Q., van Dam, R. M., Sampson, L. A., Rimm, E. B., Holmes, M. D., Willett, W. C., Hu, F. B., and Sun, Q. Association between dietary whole grain intake and risk of mortality: Two large prospective studies in US men and women. J. Am. Med. Assoc. Intern. Med. 175:373, 2015.

35. Bodinham, C. L., Hitchen, K. L., Youngman, P. J., Frost, G. S., and Robertson, M. D. Short-term effects of whole-grain wheat on appetite and food intake in healthy adults: A pilot study. Br. J. Nutr. 106:327, 2011.

36. Lankinen, M., Schwab, U., Seppänen-Laakso, T., Mattila, I., Juntunen, K., Mykkänen, H., Poutanen, K., Gylling, H., and Oresic, M. Metabolomic analysis of plasma metabolites that may mediate effects

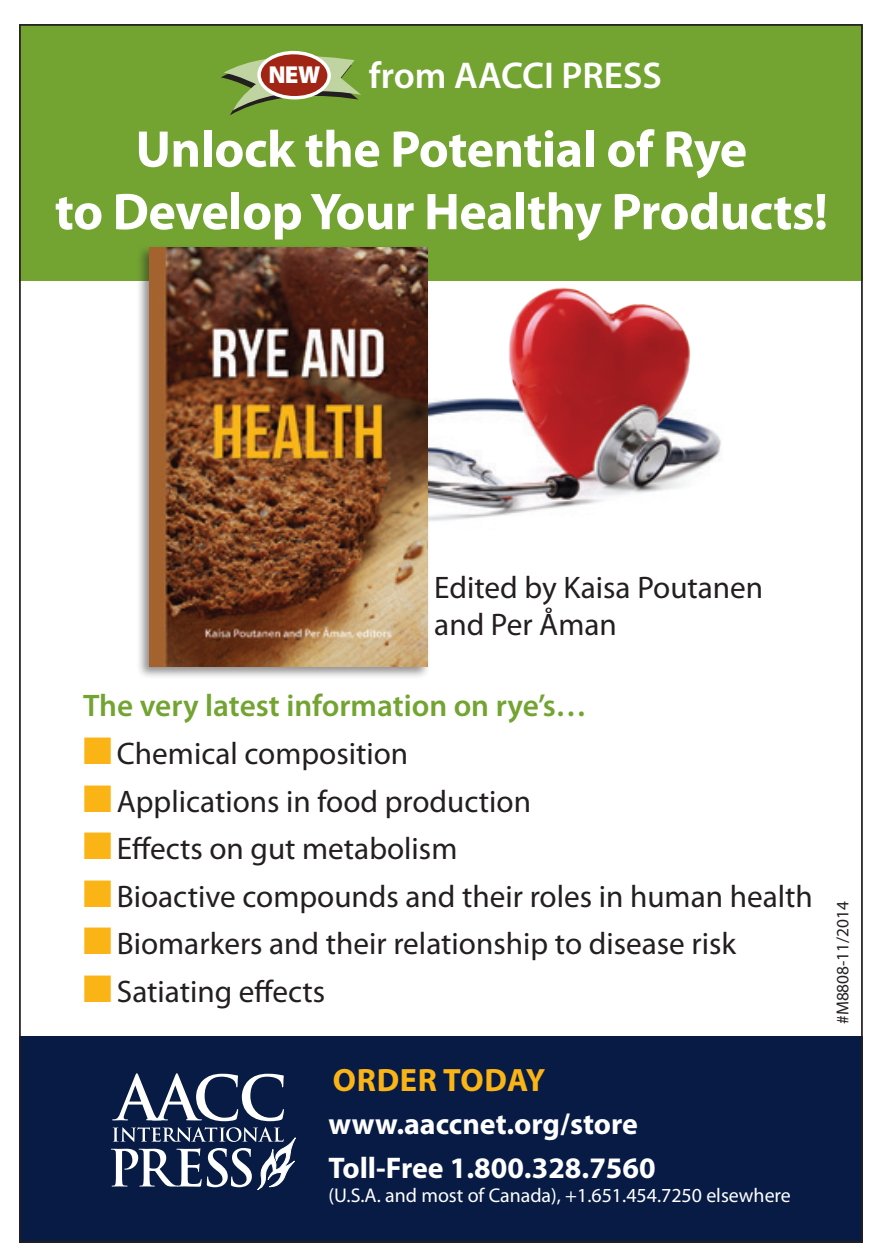

of rye bread on satiety and weight maintenance in postmenopausal women. J. Nutr. 141:31, 2011.

37. Landberg, R., Andersson, S. O., Zhang, J. X., Johansson, J. E., Stenman, U. H., Adlercreutz, H., Kamal-Eldin, A., Aman, P., and Hallmans, G. Rye whole grain and bran intake compared with refined wheat decreases urinary C-peptide, plasma insulin, and prostate specific antigen in men with prostate cancer. J. Nutr. 140:2180, 2010.

38. Johansson, E. V., Nilsson, A. C., Östman, E. M., and Björck, I. M. Effects of indigestible carbohydrates in barley on glucose metabolism, appetite and voluntary food intake over $16 \mathrm{~h}$ in healthy adults. Nutr. J. 12:46, 2013.

39. Zhang, J., Li, L., Song, P., Wang, C., Man, Q., Meng, L., Cai, J., and Kurilich, A. Randomized controlled trial of oatmeal consumption versus noodle consumption on blood lipids of urban Chinese adults with hypercholesterolemia. Nutr. J. 11:54, 2012.

40. Zhang, G., Pan, A., Zong, G., Yu, Z., Wu, H., et al. Substituting white rice with brown rice for 16 weeks does not substantially affect metabolic risk factors in middle-aged Chinese men and women with diabetes or a high risk for diabetes. J. Nutr. 141:1685, 2011.

41. Brownlee, I. A., Moore, C., Chatfield, M., Richardson, D. P., Ashby, P., Kuznesof, S. A., Jebb, S. A., and Seal, C. J. Markers of cardiovascular risk are not changed by increased whole-grain intake: The WHOLEheart Study, a randomised, controlled dietary intervention. Br. J. Nutr. 104:125, 2010.

42. Kelly, S. A. M., Summerbell, C. D., Byrnes, A., Whittaker, V., and Frost, G. Wholegrain cereals for coronary heart disease. Cochrane Database Syst. Rev. April 18(2):CD005051, 2007.

43. Shin, S., Sung, J., and Joung, H. A fruit, milk and whole grain dietary pattern is positively associated with bone mineral density in Korean healthy adults. Eur. J. Clin. Nutr. 69:442, 2015.

44. Song, S., Paik, H. Y., and Song, Y. High intake of whole grains and beans pattern is inversely associated with insulin resistance in healthy Korean adult population. Diabetes Res. Clin. Pract. 98:e28, 2012.

45. Muhihi, A., Gimbi, D., Njelekela, M., Shemaghembe, E., Mwambene, K., et al. Consumption and acceptability of whole grain staples for lowering markers of diabetes risk among overweight and obese Tanzanian adults. Global Health 9:26, 2013.

46. Cleveland, L. E., Moshfegh, A. J., Albertson, A. M., and Goldman, J. D. Dietary intake of whole grains. J. Am. Coll. Nutr. 19:331S, 2000.

47. Harnack, L., Walters, S. A., and Jacobs, D. R., Jr. Dietary intake and food sources of whole grains among US children and adolescents: Data from the 1994-1996 Continuing Survey of Food Intakes by Individuals. J. Am. Diet. Assoc. 103:1015, 2003.

48. Weise, E. The hard truth about stone-ground flour. Published online at http://usatoday30.usatoday.com/news/health/2006-03-13stone-ground-flour_x.htm. USA Today, 2006.

49. U.S. Food and Drug Administration. Proposed standards of identity of flour, enriched flour, bromated flour, enriched bromated flour, self-rising flour, enriched self-rising flour, farina, enriched farina and semolina. Whole Grains No. 58-64. Fed. Reg. 6:1729, 1941.

50. Kozmin, P. A. Flour Milling, A Theoretical and Practical Handbook of Flour Manufacture for Millers, Millwrights, Flour-Milling Engineers and Others Engaged in the Flour Milling Industry. Van Nostrand, New York, 1917.

51. Lopez, H. W., Duclos, V., Coudray, C., Krespine, V., Feillet-Coudray, C., Messager, A., Demigné, C., and Rémésy, C. Making bread with sourdough improves mineral bioavailability from reconstituted whole wheat flour in rats. Nutrition 9:524, 2003.

52. Carpenter, K. J. The relationship of pellagra to corn and the low availability of niacin in cereals. Exper. Suppl. 44:197, 1983.

53. Nierle, W. Verteilung der essentiellen Aminosauren in Getreidemahlfraktionen. Getreide Mehl Brot 38:103, 1984.

54. Gray's Grist Mill. How the mill works. Published online at www. graysgristmill.com/how-the-mill-works. The Mill, Westport, MA, 2015. 
55. INRA. New flours for organic bread. Published online at www.inra. fr/en/Partners-and-Agribusiness/Results-Innovations-Transfer/ All-the-news/New-flours-for-organic-bread. INRA, Paris Cedex, 2008.

56. Aubert, C. Farine fraiche et moulins familiaux. Quatre Saisons Jardinage 56(Mai/Juin), 1989. Baker's Dig. 36:50, 1962. (Cited by Campbell, J., Hauser, M., and Hill, S. Nutritional characteristics of organic, freshly stone-ground, sourdough \& conventional breads. Ecological Agriculture Projects Publication 35.) Published online at http://eap.mcgill.ca/publications/EAP35.htm. EAP, McGill University, Ste-Anne-de-Bellevue, Canada, 1991.

57. Prabhasankar, P., and Rao, P. H. Effect of different milling methods on chemical composition of whole wheat flour. Eur. Food Res. Technol. 213:465, 2001.

58. Hurrell, R., Ranum, P., de Pee, S., Biebinger, R., Hulthen, L., Johnson, Q., and Lynch, S. Revised recommendations for iron fortification of wheat flour and an evaluation of the expected impact of current national wheat flour fortification programs. Food Nutr. Bull. 31(Suppl. 1):S7, 2010.

59. Trinidad, T. P., Mallillin, A. C., Sagum, R. S., Briones, D. P., Encabo, R. R., and Juliano, B. O. Iron absorption from brown rice/brown rice-based meal and milled rice/milled rice-based meal. Int. J. Food Sci. Nutr. 60:688, 2009.

60. Cook, J. D., Reddy, M. B., Burri, J., Juillerat, M. A., and Hurrell, R. F. The influence of different cereal grains on iron absorption from infant cereal foods. Am. J. Clin. Nutr. 165:964, 1997.

61. Fretzdorff, B., and Weipert, D. Phytic acid and cereals and cereal products. I: Phytic acid and phytase in rye and rye products. Z. Lebensm.-Unters. -Forsch. 182:287, 1986.

62. Food and Nutrition Board, Institute of Medicine. Dietary Reference Intakes for Vitamin A, Vitamin K, Arsenic, Boron, Chromium, Copper, Iodine, Iron, Manganese, Molybdenum, Nickel, Silicon, Vanadium, and Zinc. National Academy Press, Washington, DC, 2001.

63. Gibson, R. S., Bailey, K. B., Gibbs, M., and Ferguson, E. L. A review of phytate, iron, zinc, and calcium concentrations in plant-based complementary foods used in low-income countries and implications for bioavailability. Food Nutr. Bull. 31(Suppl. 2):S134, 2010.

64. Latunde-Dada, G. O., Li, X., Parodi, A., Edwards, C. H., Ellis, P. R., and Sharp, P. A. Micromilling enhances iron bioaccessibility from wholegrain wheat. J. Agric. Food Chem. 62:11222, 2014.

65. Yu, B. H., and Kies, C. Niacin, thiamin, and pantothenic acid bioavailability to humans from maize bran as affected by milling and particle size. Plant Foods Hum. Nutr. 43:87, 1993.

66. Izydorzyk, M. Molecular and functional properties of cereal glucans. Mini-symposium on $\beta$-Glucans, Oats, and Barley. AACCI Northwest Section, Minneapolis, MN, 2011. Published online at www.grainscanada.gc.ca/cgc-ccg/grl-lrg/ragrl-arlrg/2011-12/ragrlarlrg-05-eng.htm. Canadian Grain Commission, Winnipeg, MB, Canada, 2012.

67. Kletke, J. B., Izydorczyk, M. S., and Dexter, J. E. Optimization of hull-less barley roller milling to produce fractions suitable as functional food ingredients. Tec. Molitoria 60:1211, 2009.

68. Dexter, J. E., Izydorczyk, M. S., Preston, K. R., and Jacobs, M. The enrichment of bread with a fibre-rich fraction derived from roller milling of hull-less barley. Adv. Cereal Sci. Technol. 2:467, 2004.

69. Izydorczyk, M. S., McMillan, T., Bazin, S., Kletke, J., Dushnicky, L., Dexter, J., Chepurna, A., and Rossnagel, B. Milling of Canadian oats and barley for functional food. Oat bran and barley fibre-rich fractions. Can. J. Plant Sci. 94:573, 2014.

70. Kiryluk, J., Kawka, A., Gasiorowski, H., Chalcarz, A., and Anioła, J. Milling of barley to obtain beta-glucan enriched products. Nahrung 44:238, 2000.

71. Åman, P., Rimsten, L., and Andersson, R. Molecular weight distribution of $\beta$-glucan in oat-based foods. Cereal Chem. 81:356, 2004.

72. Prakash, J. Rice bran proteins: Properties and food uses. Crit. Rev. Food Sci. Nutr. 36:537, 1996.

73. Kwiterovich, P. O., Jr. The effect of dietary fat, antioxidants, and prooxidants on blood lipids, lipoproteins, and atherosclerosis. J. Am. Diet. Assoc. 97(Suppl. 7):S31, 1997.

74. Gebruers, K., Dornez, E., Bedő, Z., Rakszegi, M., Frás, A., Boros, D., Courtin, C. M., and Delcour, J. A. Environment and genotype effects on the content of dietary fiber in wheat in the HEALTHGRAIN diversity screen. J. Agric. Food Chem. 58:9353, 2010.

75. Gebruers, K., Dornez, E., Boros, D., Frás, A., Dynkowska, W., Bedö, Z., Rakszegi, M., Delcour, J. A., and Courtin, C. M. Variation in the content of dietary fiber and components thereof in the HEALTHGRAIN diversity screen. J. Agric. Food Chem. 56:9740, 2008.

76. Batifoulier, F., Verny, M.-A., Chanliaud, E., Remesy, C., and Demigne, C. Variability of B vitamin concentrations in wheat grain, milling fractions and bread products. Eur. J. Agron. 25:155, 2006.

77. Martinez-Villaluenga, C., Michalska, A., Frias, J., Piskula. M. K., Vidal-Valverde, C., and Zieliński, H. Effect of flour extraction rate and baking on thiamine and riboflavin content and antioxidant capacity of traditional rye bread. J. Food Sci. 274:C49, 2009.

78. Batifoulier, F., Verny, M.-A., Chanliaud, E., Remesy, C., and Demigne, C. Effect of different breadmaking methods on thiamine, riboflavin and pyridoxine contents of wheat bread. J. Cereal Sci. 42:101, 2005.

79. van der Kamp, J. W. The need for a whole grain definition in Europe Published online at www.icc.or.at/webfm_send/114. ICC, Vienna, 2011.

80. Katina, K., Selinheimo, E., Lehtinen, P., Flander, L. P., Laitila, A., Juvonen, R., Piironen, V., Edelmann, M., Kariluoto, S., and Poutanen, K. Bioprocessing of bran for improved functionality. Page 32 in: Enhancing Health Benefits of Cereal Foods -Results, Perspectives, Challenges. Published online at www.healthgrain.org/ webfm_send/56. VTT Technical Research Centre of Finland, VTT, Finland, 2010. 